\title{
¿Review
}

\section{Nickel-Catalyzed Hydrocyanation of Allenes and Its Application}

\author{
Shigeru Arai \\ Graduate School of Pharmaceutical Sciences, Chiba University; \\ 1-8-1 Inohana, Chuo-ku, Chiba 260-8675, Japan. \\ Received December 3, 2018
}

\begin{abstract}
Cyano (CN) groups are equivalent to carbonyl as well as amino- and hydroxymethyl groups. Therefore, their catalytic introduction under metal catalysis is an important issue in synthetic organic chemistry. Nicatalyzed hydrocyanation is one of the most well-investigated, powerful tools for installing a $\mathrm{CN}$ group. However, it is still difficult to control chemo- and regioselectivity. In this review, the author uses allenes to enable regio-, stereo-, and face-selective transformations to natural product synthesis and axial chirality transfer.
\end{abstract}

Key words alkaloid; allene; catalysis; cyanation; cyclization; nickel

\section{Introduction}

Cyano $(\mathrm{CN})$ groups are the synthetic equivalent of carboxylic acids along with formyl and aminomethyl groups and, due to their biological activities, they play important roles in many pharmaceuticals. ${ }^{1)}$ Therefore, their introduction to organic molecules, particularly by catalytic protocols, has been a major challenge in synthetic chemistry. In general, cyanation has been achieved by nucleophilic addition using cyanides [hydrogen cyanide (HCN), trimethylsilyl cyanide (TMSCN), and $\left.\mathrm{Me}_{2} \mathrm{C}(\mathrm{OH}) \mathrm{CN}\right]$ to electron-deficient $\mathrm{C}-\mathrm{C}, \mathrm{C}-\mathrm{O}$, and $\mathrm{C}-\mathrm{N}$ multiple bonds. On the other hand, transition metal catalysis offers various cyanation protocols to use nonpolarized $\mathrm{C}-\mathrm{C}$ multiple bonds with $\mathrm{X}-\mathrm{CN}\left(\mathrm{X}=\mathrm{H},{ }^{2-5}\right)$ aryl, ${ }^{6}$ ) fluoroarene, $\left.{ }^{7}\right)$ acyl, ${ }^{8,9)}$ alkyl, ${ }^{10)}$ allyl, ${ }^{11)}$ alkynyl, ${ }^{12)} \mathrm{N},{ }^{13)} \mathrm{O},{ }^{14,15)} \mathrm{Si},{ }^{16)} \mathrm{Ge},{ }^{17}$ $\mathrm{B},{ }^{18)} \mathrm{S},{ }^{19)} \mathrm{Br}^{20)} \mathrm{I}^{21)}$ and $\mathrm{Sn}^{22)}$ ) under metal catalysis (Chart 1). Other approaches for multicomponent connective cyanation to install $\mathrm{CN},{ }^{23-25)} \mathrm{CF}_{3},{ }^{26)} \mathrm{Cl}^{27)}$ and $\mathrm{S}^{28)}$ functionalities have been reported.

The oldest and most thoroughly investigated cyanation is Ni-catalyzed hydrocyanation $(\mathrm{X}=\mathrm{H})$, which enables the use of olefins, ${ }^{29,30)}$ alkynes, ${ }^{31)}$ and conjugated dienes, ${ }^{32)}$ and thus is considered to be one of the most significant, fundamental cyanation reactions. On the other hand, perfect, predictable regioselectivity can be observed only with limited substrates such as styrene derivatives. ${ }^{33)}$ This limitation reflects a lack of generality, and regiocontrolled hydrocyanation is still a key problem to be solved even 40 years after its discovery.

Most previous reports on hydrocyanation reactions summarized the substrate scope. No previous ones evaluated the relative reactivities of $\mathrm{C}-\mathrm{C}$ multiple bonds in detail. Therefore, this study investigated the reactivity order of $\mathrm{C}-\mathrm{C}$ multiple

This review of the author's work was written by the author upon receiving the 2018 Pharmaceutical Society of Japan Award for Divisional Scientific Promotion. bonds in Ni-catalyzed hydrocyanation. This approach should help to improve the synthetic strategy and contribute to rational reaction design for the facile, rapid synthesis of useful molecules.

\section{Reaction between Allenes and Alkynes}

2.1. Hydrocyanative Cyclization Using Enyne and Allene-Ynes To clarify the relative reactivities of olefins and alkynes, 1a was initially examined for hydrocyanative cyclization (Chart 2). Although 4 unsaturated carbons in 1a could be reactive for the initial hydrometallation, the single product 2a was exclusively obtained through this cyclization. ${ }^{34)}$ Initial $\mathrm{C}-\mathrm{H}$ bond formation preferably occurs at a terminal methylene of 1a, and subsequent 5-exo-cyclization gives 3a-1. Sequential formation of a Ni-carbene intermediate (3a-2), followed by reductive elimination, gives $\mathbf{2} \mathbf{a}$ as a single isomer. The origin of the olefinic stereochemistry would be steric repulsion between the triisopropylsilyl (TIPS) and $c$-Hex groups to promote $\mathrm{C}-\mathrm{C}$ bond rotation ${ }^{35}$ in $\mathbf{3 a - 2}$ before reductive elimination from 3a-3 to form a $\mathrm{C}-\mathrm{CN}$ bond (anti-carbocyanation).

Bulky substituents were essential for higher selectivity in the above hydrometallation, as were harsh reaction conditions $\left(150^{\circ} \mathrm{C}\right)$. This result prompted the use of more reactive $\mathrm{C}-\mathrm{C}$ multiple bonds, and $\mathbf{4 a}$ and $\mathbf{4 b}$ were next used in a competitive experiment (Chart 3). Interestingly, $\mathbf{4 a}$ exclusively reacted at $100^{\circ} \mathrm{C}$ to give three products $(\mathbf{5}-\mathbf{7 a})$, and $\mathbf{4 b}$ was fully recovered. This result suggests that: 1) allenyl double bonds are more reactive than $\mathrm{C}-\mathrm{C}$ triple bonds; and 2) an $s p$ carbon of

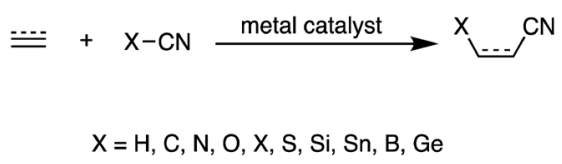

Chart 1. Metal-Catalyzed Cyanation of $\mathrm{C}-\mathrm{C}$ Multiple Bonds 


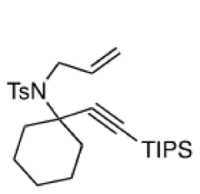

$1 \mathbf{a}$
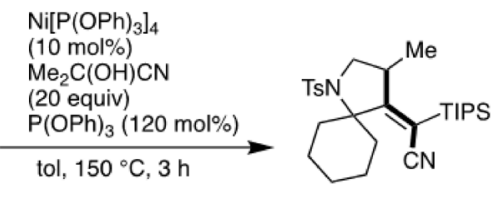

2a: $65 \%$ (single isomer) with 1a: $13 \%$

TIPS: $\mathrm{Si}(\mathrm{i}-\mathrm{Pr})_{3}$
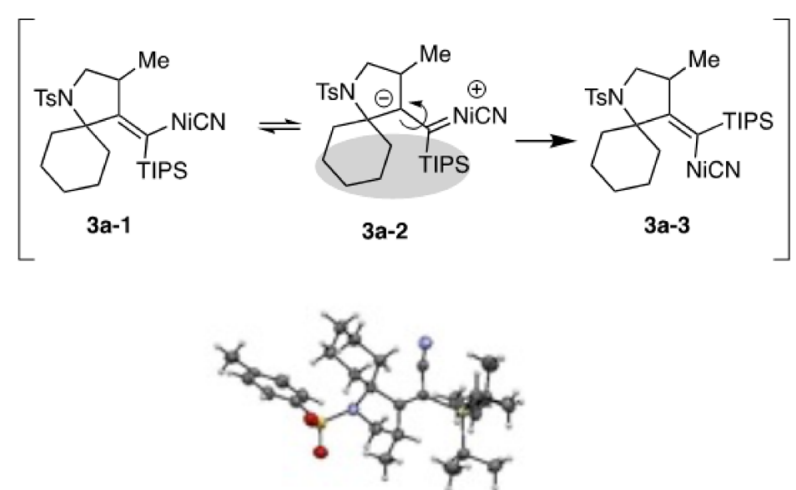

$2 \mathbf{a}$

Chart 2. Hydrocyanative Cyclization of 1a

(Color figure can be accessed in the online version.)

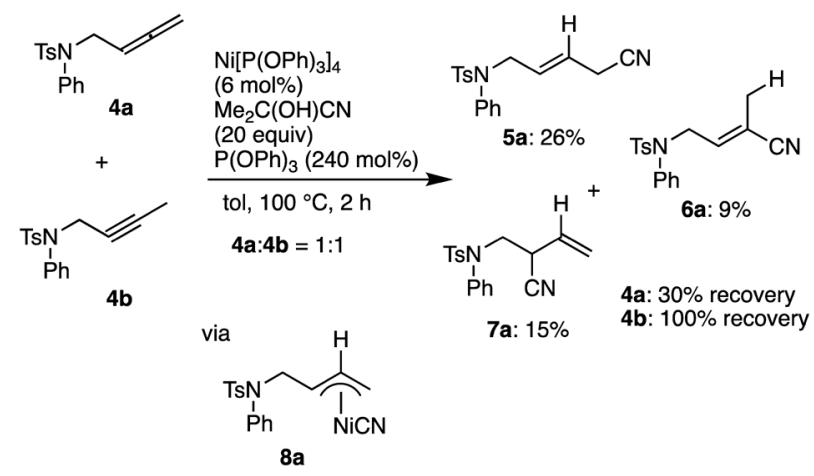

Chart 3. Hydrocyanation of $\mathbf{4 a}$ and $\mathbf{4 b}$

4a is more favored in $\mathrm{C}-\mathrm{H}$ bond formation.

This observation indicates that these two functionalities are easily discriminable. Therefore allene-ynes (9) were next examined as cyclization precursors. The reaction would be triggered by regioselective hydrometallation to allene, and a single reaction pathway could be proposed. It was found that various allene-ynes were smoothly converted to single cycli-
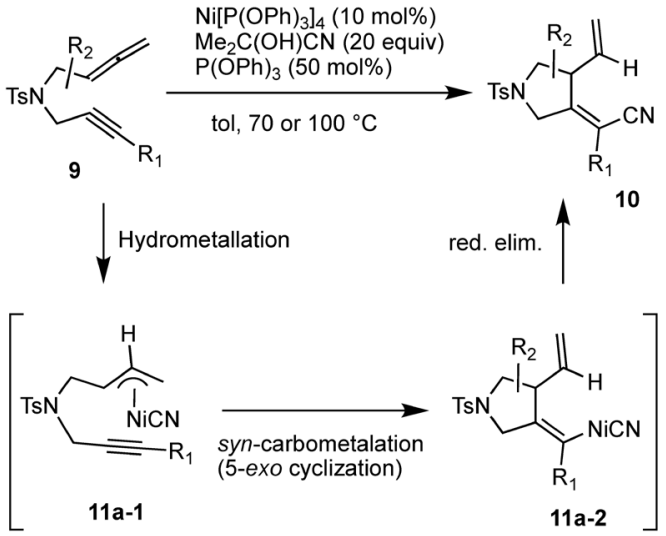<smiles>[R16]C([Y10])=C1CN([AlH2])CC1C=C</smiles><smiles>[R]/C(C#N)=C1/CN([As])CC1C(=C)C</smiles>

10a: $R=M e: 64 \%$ 10b: $R=t-B u: 70 \%$ 10c: $R=$ TMS: $67 \%$ 10d: $\mathrm{R}=\mathrm{Me}_{2} \mathrm{C}(\mathrm{OH}): 52 \%$ 10e: $\mathrm{R}=\mathrm{Me}_{2} \mathrm{C}(\mathrm{OMe}): 43 \%$

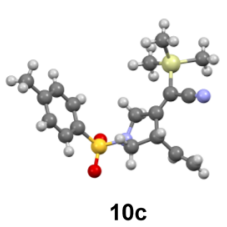<smiles>C=CC1C(=C(C#N)C#N)C[15N]C1C</smiles>

10j: $38 \%$ $(d r=3.4: 1)$

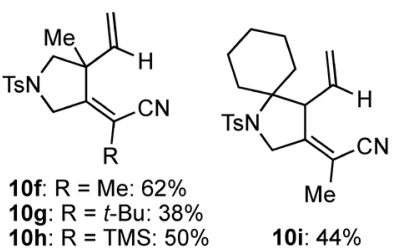

10f: $R=$ Me: $62 \%$ 10g: $R=t-B u: 38 \%$ 10h: $R=$ TMS: $50 \%$<smiles>CC(C#N)=C1CN([As])CC1C=COCC(C)C</smiles>

10I: $64 \%$

(cis:trans $=1: 1.3)$<smiles>CC(C#N)=C1CN([Al-])CC1(C)/C=C/c1ccccc1</smiles>
10k: $32 \%\left(150{ }^{\circ} \mathrm{C}\right)$<smiles>C=CC1CC(C(=O)OCC)(C(=O)OCC)CC1=C(C)C#N</smiles>

10m: $71 \%$

Chart 4. Hydrocyanative Cyclization Using 9

(Color figure can be accessed in the online version.)

zation products $(\mathbf{1 0 a}-\mathbf{m})$, including 5-membered carbo- and heterocycles with silyl, hydroxy, and amide functionalities as well as quaternary carbons. The proposed catalytic cycle initiates regioselective $\mathrm{C}-\mathrm{H}$ bond formation at an $s p$ carbon of 9, and the resulting formation of a $\pi$-allyl $\mathrm{Ni}$ intermediate (11a-1), followed by syn-carbometallation to alkyne, gives 10 after reductive elimination from 11a-2. Their structure reasonably explains the regio- and stereoselectivity of $\mathrm{C}-\mathrm{H}$ and $\mathrm{C}-\mathrm{CN}$ bonds in $\mathbf{1 0 a}-\mathbf{m}$ based on the proposed reaction

\section{Biography}

Dr. Shigeru Arai was born in Sapporo, Japan, in 1968. He received a B.S. from Hokkaido University (1992), where he worked with Prof. Masakatsu Shibasaki. He moved to the University of Tokyo Graduate School to study asymmetric catalysis using rare earth metal complexes under the direction of Prof. Shibasaki and received a Ph.D. in 1998. In 1996, Dr. Arai started his academic career under Prof. Takayuki Shioiri at Nagoya City University. He contributed to studies on asymmetric phase-transfer catalysis using chiral ammonium salts and its application. He became an associate professor at Chiba University (Prof. Atsushi Nishida) in December 2001. He was also a member of the Chemistry Department at MIT (Prof. G.C. Fu) as a postdoctoral fellow (JSPS) during 1999-2000. His research focuses on natural product synthesis and reaction development under transition-metal

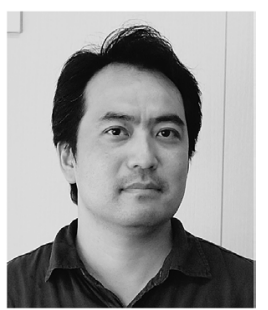

Shigeru Arai catalysis. 

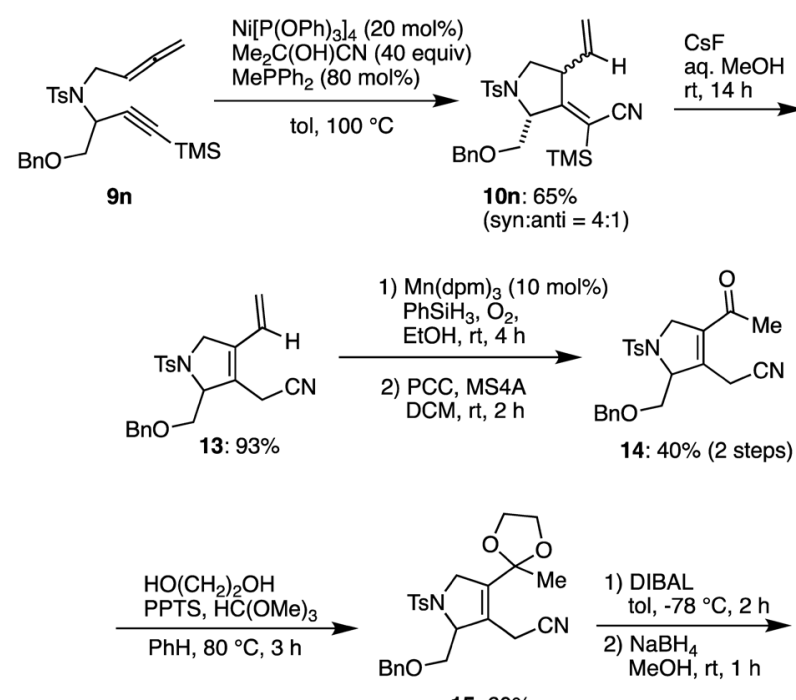

15: $60 \%$
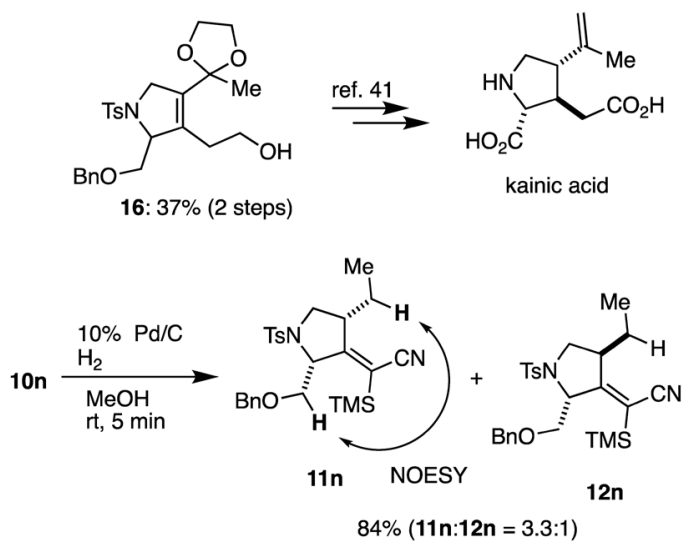

Chart 5. Formal Synthesis of ( \pm )-Kainic Acid

pathway $^{36,37)}$ (Chart 4).

The use of 9n as a cyclization precursor in the formal synthesis of $( \pm)$-kainic acid $^{38,39)}$ was investigated next. A $\mathrm{BnOCH}_{2}$ group is a synthetic equivalent of carboxylic acid, and the hydrocyanative cyclization of 9n using $\mathrm{PMePh}_{2}$ proceeded smoothly to give a mixture of stereoisomers of 10n in $65 \%$ yield (syn-anti $=4: 1$ ). A major diastereomer was assigned to be syn by nuclear Overhauser effect spectroscopy (NOESY) after conversion to $11 \mathbf{n}$ and $\mathbf{1 2 n}$ by hydrogenation. Treatment of 10n with CsF promoted desilylation and olefin isomerization to give $\mathbf{1 3}$ in $93 \%$ yield, and subsequent $\mathrm{Mu}-$ kaiyama hydration $^{40}$ and pyridinium chlorochromate (PCC) oxidation gave 14 in $40 \%$ yield in 2 steps. Next, acetalization and sequential reduction of a cyano group to Trost's intermediate $16^{41)}$ furnished the formal synthesis of $( \pm)$-kainic acid (Chart 5).

2.2. Multicomponent Coupling Reaction Using Allenes and Alkynes Allenes and alkynes are also discriminable when they are located in different molecules. The reaction could be triggered by chemoselective hydrometallation to allene, and the resulting organonickel species could act as a nucleophile to the electrophilic $\mathrm{C}-\mathrm{C}$ triple bonds through an intermolecular reaction. Some advantages of this protocol are operational simplicity and less metal waste because organometallic species are catalytically generated. To demonstrate such a cross-coupling reaction, the regiocontrol of $\pi$-allyl $\mathrm{Ni}(\mathrm{II})$
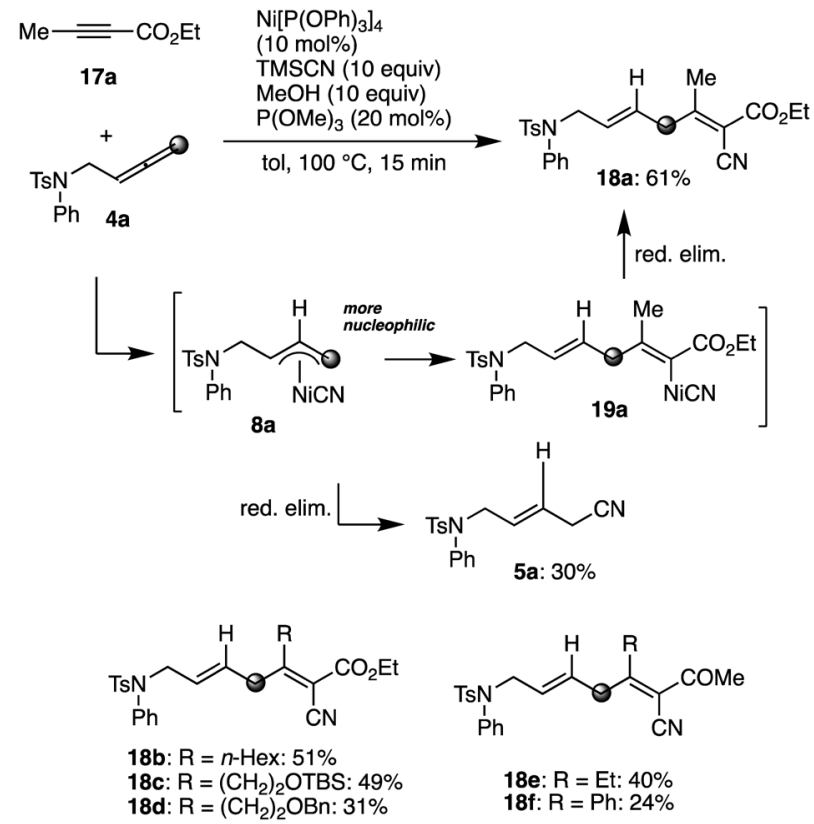

Chart 6. Hydrocyanative 3-Component Coupling Reaction

species in nucleophilic attack and the choice of electrophilic $\mathrm{C}-\mathrm{C}$ triple bonds were key issues. The former was addressed by the use of a monosubstituted allene such as $\mathbf{4 a}$, and the latter was resolved by the use of alkynoates, as shown in Chart 6.

The reactive allylic $s p^{2}$ carbons in $\mathbf{8 a}$ were discriminable in $s y n$-carbocyanation. A less-substituted $s p^{2}$ carbon is more suitable for the formation of a $\mathrm{C}-\mathrm{C}$ bond via conjugated addition, and 18a was obtained in a regio- and stereoselective fashion. A side product was characterized to be $\mathbf{5 a}$, which was given by reductive elimination from $\mathbf{8 a}$. This result supports the reaction pathway described in Chart 6 . The substrate scope revealed that alkynoates as well as alkynylketones bearing aryl and oxygen functionalities were suitable in regio- and stereoselective cross-coupling reactions to give $\mathbf{1 8 a}-\mathbf{f}^{36,42)}$

2.3. Cyclization Using Bis-allenes Bis-allenes are also suitable for this 5-exo cyclization. Symmetric bis-allenes [20a: $\left.\mathrm{R}=\mathrm{H}, \mathrm{X}=\mathrm{NTs}, \mathbf{2 0 b}: \mathrm{R}=\mathrm{H}, \mathrm{X}=\mathrm{C}\left(\mathrm{CO}_{2} \mathrm{Et}\right)_{2}\right]$ are smoothly converted to the corresponding adducts $(\mathbf{2 1 a}, \mathbf{b})$ through regioselective cyclization, and their stereochemistry was assigned to be $s y n{ }^{43)}$ Nonsymmetric substrates such as $\mathbf{2 0 c}-\mathbf{e}$ were also applicable. Hydrometallation prefers less-hindered or lesssubstituted allenes to form a $\mathrm{C}-\mathrm{H}$ bond at $s p$ carbons while avoiding steric repulsion ${ }^{37)}$ (Chart 7).

\section{Reaction of Allenes}

3.1. Hydrocyanation of Simple Allenes The above results show that $\mathrm{C}-\mathrm{C}$ triple bonds are essential for regio- and stereoselective hydrometallation to discriminate allenyl $\mathrm{C}-\mathrm{C}$ double bonds in hydrocyanative cyclization and cross-coupling reactions. Is it possible to control the regiochemistry using simple allenes without the assistance of any $\mathrm{C}-\mathrm{C}$ triple bonds? Only one example of this approach was reported, which described lower selectivity using mono- and disubstituted allenes. ${ }^{44)}$ Similar results were achieved to give a mixture of 5-7 and 22 with the use of $\mathbf{4 a}$, c, although this selectivity was dramatically improved when $\mathbf{4 d}$ was used instead. This latter 


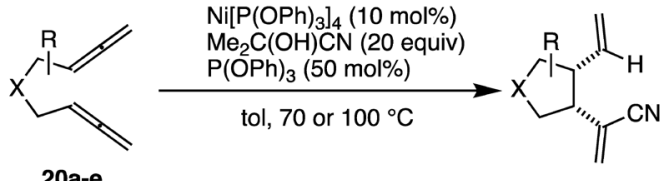

20a-e<smiles>[X]C(=C)[C@@H]1C[C@H](C([CH])=C)[C@H]1C</smiles>

21a: $X=N T s: 66 \%$ 21b: $X=C\left(\mathrm{CO}_{2} \mathrm{Et}\right)_{2}: 60 \%$<smiles>C=CC1CCC(C)[C@H](C)C1C(C)C</smiles>

21c-1: $66 \%$ $(\alpha: \beta=3: 2)$<smiles>C=C(C#N)[C@H]1CN([AlH2])C2(CCCCC2)[C@H]1C(=C)C</smiles>

21d-1: $45 \%$ 21a-e<smiles>C=C(C#N)[C@H]1CN([AsH3])C(C)[C@H]1C(=C)C</smiles>

21c-2: $15 \%$<smiles>C=C[C@@H]1CN([As])C[C@H]1/C(C#N)=C\C</smiles>

21e: $29 \%$ $(E: Z=9: 1)$<smiles>C=CC1C(C(=C)C(=C)C)CNC12CCCCC2</smiles>

21d-2: $8 \%$

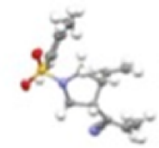

(E)-21e

Chart 7. Hydrocyanative Cyclization Using 20

(Color figure can be accessed in the online version.)

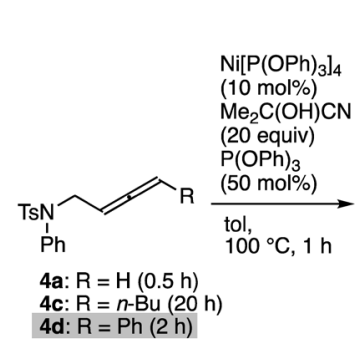

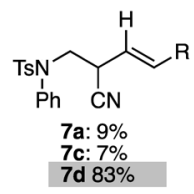
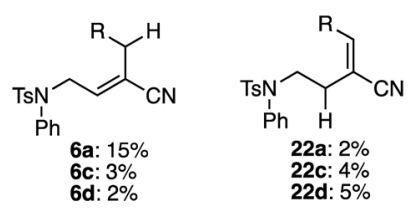

4c: $55 \%$ recovery

Chart 8. Hydrocyanation Using $\mathbf{4 a}-\mathbf{d}$

reaction was sufficiently rapid to be completed within $2 \mathrm{~h}$, and the major product (7d) with trans olefin was selectively obtained in $83 \%$ yield (Chart 8 ).

This protocol showed broad generality in regioselectivity with the use of various substrates $(\mathbf{4 e}-\mathbf{r})$ including indole, thiophene, and substituted benzene rings as well as a cyclopropane ring ${ }^{45,46)}$ (Chart 9).

Further application to the formal synthesis of $( \pm)$-quebrachamine ${ }^{47-50)}$ was achieved. ${ }^{51)}$ The cyclization precursor 4s was synthesized from 23 via 24, and then regioselective hydrocyanation using 2- $\mathrm{PyPPh}_{2}$ as an external ligand gave 25 as an exclusive product in $53 \%$ yield. Subsequent hydrogenation and alkylation gave 27 , which was converted to 28 by a reduction-nosylation sequence. A Mitsunobu reaction after removal of a tert-butyldimethylsilyl (TBS) group gave piperidine (29), which was transformed to a known intermedi-

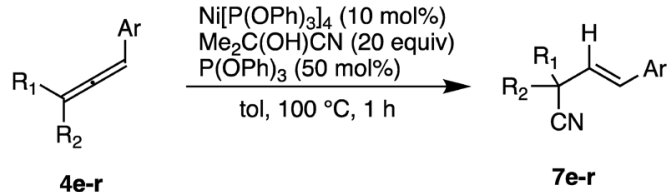

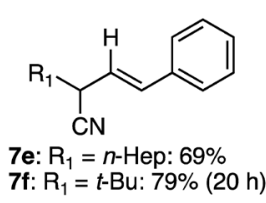<smiles>[X]c1ccc(/C=C/C(C#N)C2CCCCC2)cc1</smiles>

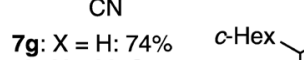
7h: $\mathrm{X}=\mathrm{MeO} \cdot 77 \%$ 7i: $\mathrm{X}=\mathrm{CF}_{3}: 76 \%$ 7j: $\mathrm{X}=\mathrm{Br}: 75 \%$

7k: $78 \%$<smiles>Cc1ccccc1/C=C/C(C#N)C=O</smiles>

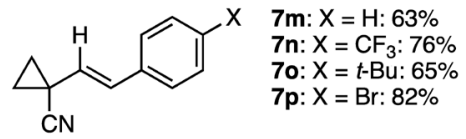<smiles>N#CC1(/C=C/c2ccc3ccccc3c2)CC1</smiles><smiles>N#CC1(/C=C\c2ccccc2)CC1</smiles>

7r: $17 \%$

Chart 9. Hydrocyanation Using $\mathbf{4 e}-\mathbf{r}$
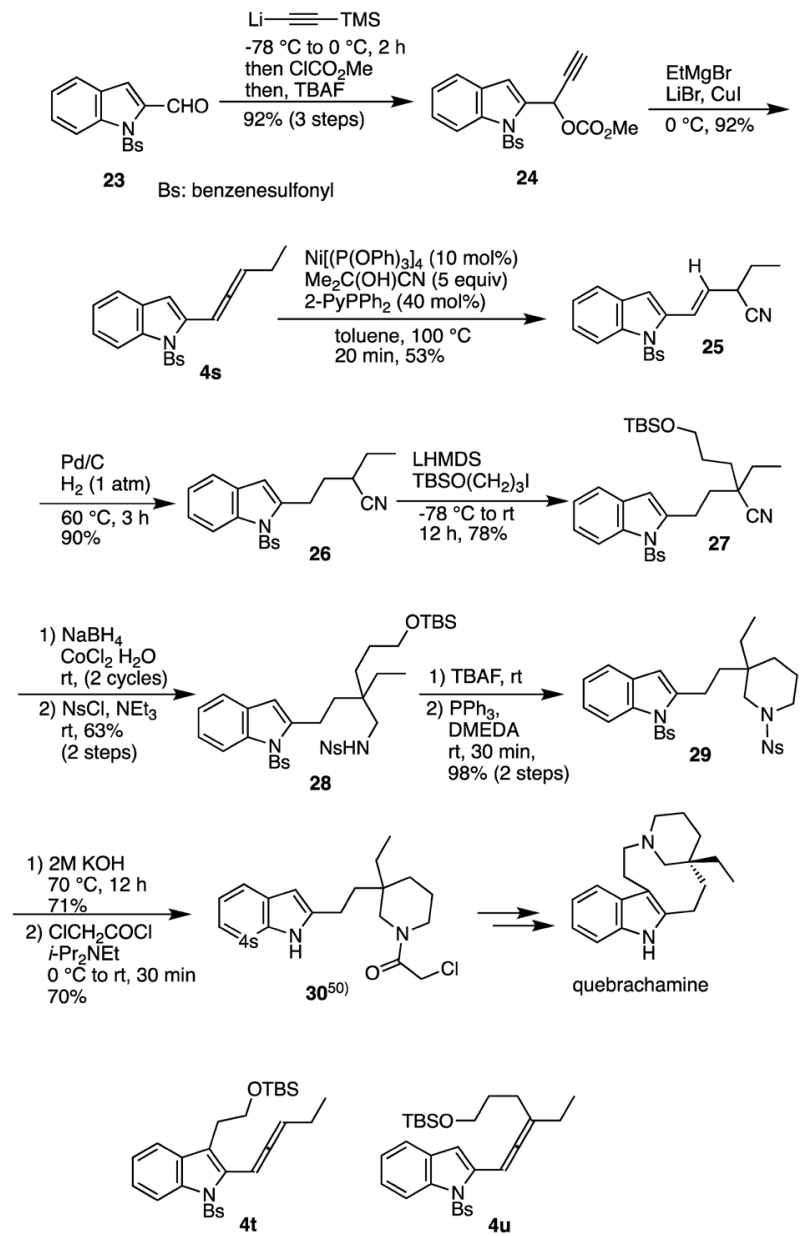

Chart 10. Formal Synthesis of ( \pm )-Quebrachamine 


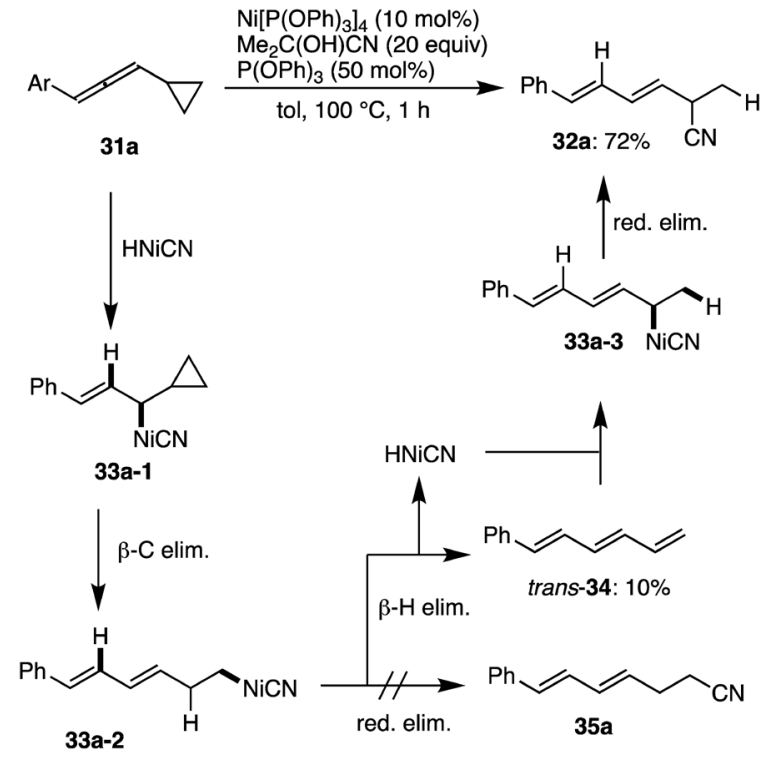

Chart 11. Hydrocyanation of $\mathbf{3 1 a}$

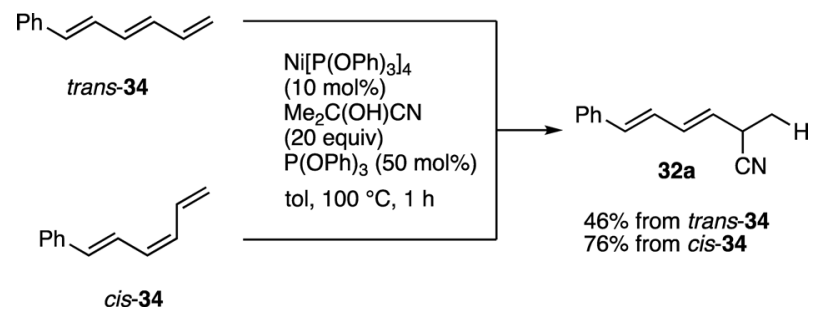

Chart 12. Hydrocyanation of $\mathbf{3 4}$

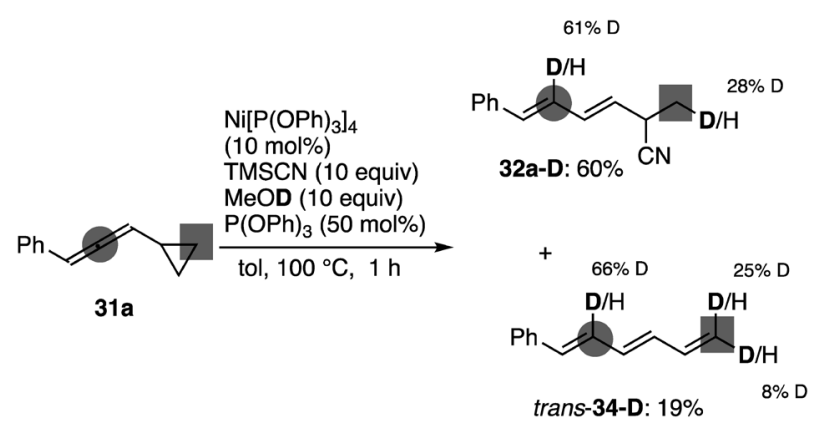

Chart 13. Hydrocyanation Using DCN

ate (30) after desulfonylation, followed by chloroacetylation. ${ }^{49)}$ The key hydrocyanation of allene was notably sensitive to the steric environment because 2,3-disubstituted indoles such as $\mathbf{4 t}$ and the tri-substituted allene $(\mathbf{4 u})$ were both inert for hydrocyanation $^{51)}$ (Chart 10).

3.2. Cyclopropane Cleavage through Hydrocyanation Since a cyclopropane ring can be cleaved by transition metal complexes, a combination of regioselective $\mathrm{C}-\mathrm{H}$ bond formation and $\mathrm{C}-\mathrm{C}$ bond cleavage would enable remote cyanation. ${ }^{45,46)}$ Arylcyclopropylallene (31a) was a suitable substrate for regioselective hydrometallation to give 33a-1, and translocation of a $\mathrm{C}-\mathrm{Ni}$ bond would be expected through the ring-opening process to 33a-2. However, the isolated product was not 35a, but rather a secondary carbonitrile (32a) together with trans-34 in respective yields of 72 and 10\% (Chart 11). The conjugated trienes (34) were both reactive in regioselec-

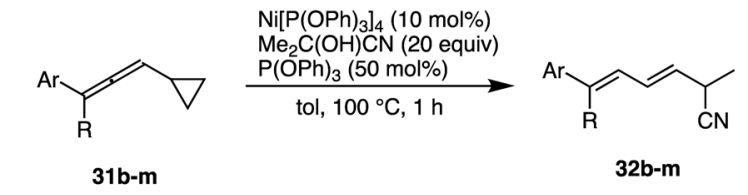<smiles>CC(C#N)/C=C/C=C/c1ccccc1</smiles>

32b: $\mathrm{R}=4-\mathrm{MeO}: 49 \%$ 32c: $R=4-\mathrm{CF}_{3}: 65 \%$ 32d: $R=4-t$-Bu: $74 \%$ 32e: $R=2-B r: 60 \%$ 32f: $R=3-B r: 67 \%$

32g: $\mathrm{R}=4-\mathrm{Br}: 68 \%$<smiles>C/C(=C\C=C\C(C)C#N)c1ccccc1</smiles>

32h: $97 \%(E: Z=6: 1)$<smiles>CC(C#N)/C=C/C=C/Br</smiles>

32i: $\mathrm{Ar}=\beta$-Nap: $76 \%$ 32j: $\mathrm{Ar}=2$-thiophenyl: $50 \%$<smiles>CC(C#N)/C=C/C=C/C1CCCCC1</smiles><smiles>C=CCNc1ccccc1/C=C/C=C/C(C)C#N</smiles>
32k: $44 \%$<smiles>CC(C#N)/C=C/C=C/CN(C)[Mg]</smiles>

32m: $50 \%$
Chart 14. Scope of Hydrocyanative Cyclopropane Cleavage

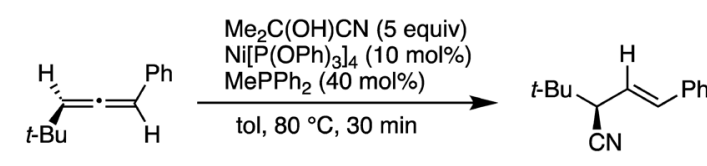

$(R)-36 \mathbf{a}(98 \%$ ee $)$ $(R)-37 a$
$97 \%$ ee, $95 \%$ yield

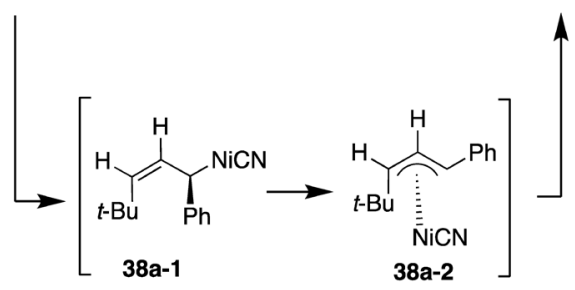

Chart 15. Chirality Transfer Using $(R)-\mathbf{3 6}$

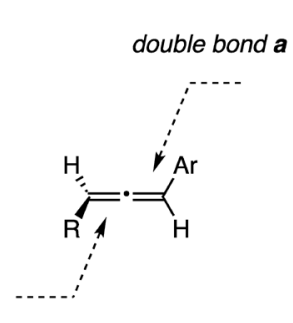

double bond $\boldsymbol{b}$

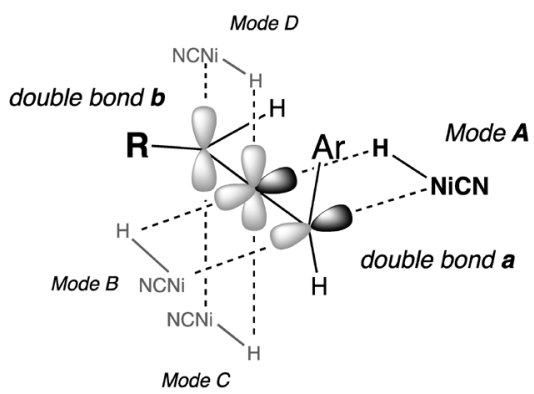

Mode C
Fig. 1. Face Selectivity in Hydronickelation

tive hydrocyanation to give $\mathbf{3 2}$ a as a sole product, suggesting that trans-34 acts as a reaction intermediate (Chart 12).

The results of a D-labeling experiment supported this mechanistic insight. In situ generation of deuterium cyanide (DCN) from TMSCN and MeOD gave the corresponding D-labeled products. As expected, C-D bonds observed in specific carbons in 32a-D and trans-34-D suggest that two regioselective hydrometallation processes are involved in the catalytic cycle $^{45,46)}$ (Chart 13).

Perfect D-incorporation in 32a and trans-34 was not observed, which indicates that $\beta$-H elimination from 33a-2 re- 

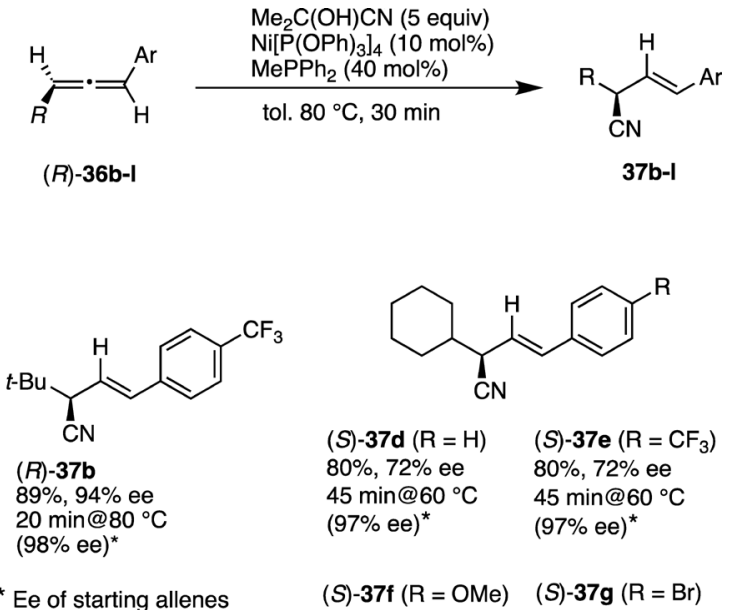

* Ee of starting allenes<smiles>COc1ccc(/C=C/[C@@H](C#N)C(C)(C)C)cc1</smiles>

(R)-37c

$84 \%, 84 \%$ ee

15 min@80 ${ }^{\circ} \mathrm{C}$ $(88 \% \text { ee })^{*}$

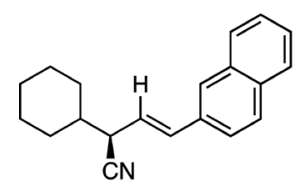

(S)-37j

$93 \%, 72 \%$ ee 30 min@60 ${ }^{\circ} \mathrm{C}$ $(96 \% \text { ee })^{*}$
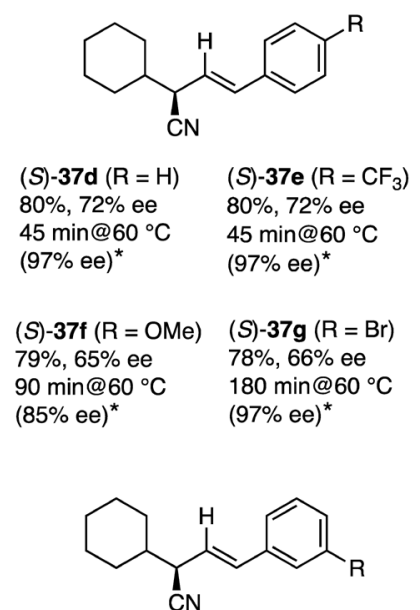

(S)-37h $\left(\mathrm{R}=\mathrm{CF}_{3}\right) \quad(\mathrm{S})-\mathbf{3 7 i}(\mathrm{R}=\mathrm{OMe})$ $84 \%, 80 \%$ ee $\quad 89 \%, 74 \%$ ee 20 min@60 ${ }^{\circ} \mathrm{C} \quad 90 \mathrm{~min} @ 60^{\circ} \mathrm{C}$ $(97 \% \text { ee })^{*} \quad(94 \% \text { ee })^{*}$

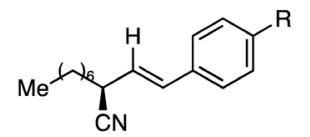

(S)-37k $(\mathrm{R}=\mathrm{H}) \quad(\mathrm{S})-37 \mathrm{I}\left(\mathrm{R}=\mathrm{CF}_{3}\right)$ $68 \%, 47 \%$ ee $74 \%, 63 \%$ ee 5 min@80 ${ }^{\circ} \mathrm{C} \quad 15 \min @ 60^{\circ} \mathrm{C}$ $(97 \% \text { ee })^{\star} \quad(96 \% \text { ee })^{*}$

Chart 16. Reaction Scope

leases HCN even in the presence of a large amount of DCN. Second hydrometallation could also be regioselective because a less-substituted terminal $\mathrm{C}-\mathrm{C}$ double bond is favorable to yield allyl $\mathrm{Ni}(\mathrm{II})$ species (33a-3), which gives 32a to retain conjugated $\mathrm{C}-\mathrm{C}$ double bonds in the products. This mechanistic proposal reasonably accounts for the observed regio- and stereochemistry of the products.

The reaction scope for this cyclopropane cleavage using various substrates (31) is summarized in Chart 14. Substituted benzenes, naphthalene, thiophene, and trisubstituted allene were all effective in regioselective remote hydrocyanation to give the corresponding dienyl carbonitriles $(\mathbf{3 2} \mathbf{b}-\mathbf{m})$ in good yield. Interestingly, alkyl substituents such as the cyclohexyl and aminomethyl groups also gave the sole secondary carbonitriles $(\mathbf{3 2 I}, \mathbf{m})$ in moderate yield. ${ }^{45,46)}$

3.3. Transfer of Axial Chirality Substituted allenes have axial chirality, which is a key property to provide chiral carbonitriles by enantioselective hydrocyanation. The use of this axial chirality to achieve central chirality has been demonstrated mainly in metal-catalyzed cyclization, ${ }^{52)}$ because two allenyl $\mathrm{C}-\mathrm{C}$ double bonds are easily discriminable through the control of ring size. On the other hand, substituted arylallenes give a single product as described above, ${ }^{45,46)}$ which suggests that the chirality of allenes could be transferred to the optical-
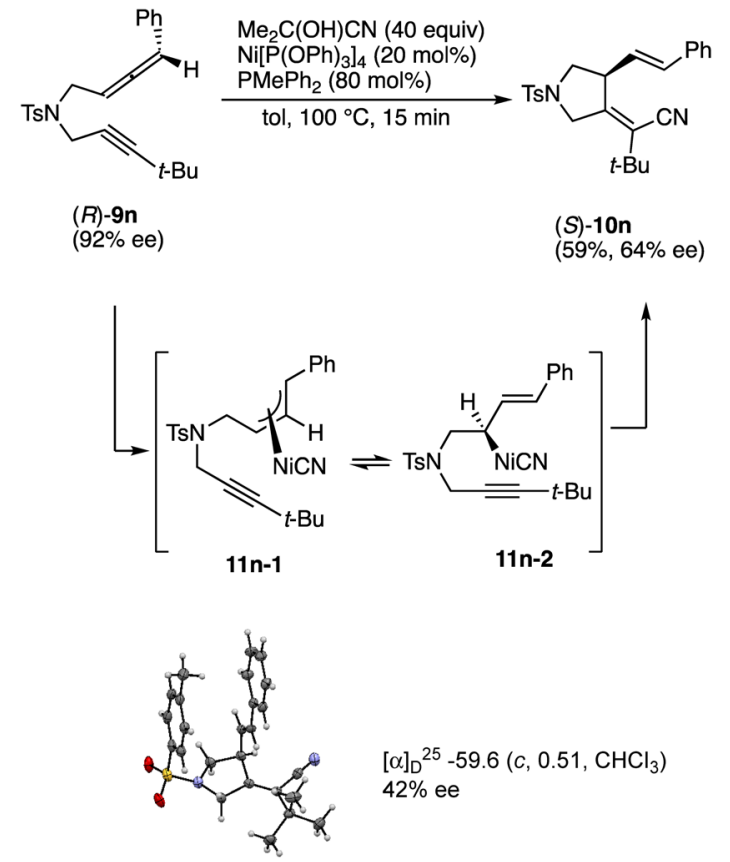

(S)-10n

Chart 17. Cyclization Using (R)-9n

(Color figure can be accessed in the online version.)

ly active $\mathrm{HCN}$ adducts by discrimination of 4 diastereotopic $\pi$-orbitals through hydrometallation (Fig. 1).

Based on the electrophilicity of an $s p$ carbon to form a $\mathrm{C}-\mathrm{H}$ bond, four hydrometallation approaches can be proposed (modes A-D). Since the steric bulk of the R group seems to be essential for selective interaction between $\mathrm{C}=\mathrm{C}$ and $\mathrm{Ni}-\mathrm{H}$ bonds, a bulky $t$ - $\mathrm{Bu}$ group was initially chosen to investigate the transfer of axial chirality.

When $(R)$-36a $(98 \%$ enantiomeric excess (ee)) was used under Ni-catalyzed hydrocyanation conditions, the corresponding HCN adduct was obtained in $95 \%$ yield with $97 \%$ $e^{53)}$ (Chart 15). This result is the first example of the use of the axial chirality of allene in enantioselective hydrocyanation. Since double bond a is estimated to be more reactive than bond $\mathrm{b}$ (Fig. 1), mode A, which avoids steric repulsion by the $\mathrm{R}$ group, is the most favored approach to give the initial $\mathrm{Ni}$ (II) intermediate (38a-1). Sequential isomerization to 38a-2 followed by reductive elimination gives $(R)-37 \mathbf{a}$ without any loss of enantioselectivity. Its absolute stereochemistry is reasonable to explain this reaction pathway.

The result of the reaction scope using various optically active allenes $(\mathbf{3 6} \mathbf{b}-\mathbf{l})$ with an $S$-configuration is summarized in Chart 16. The substituent on the benzene ring $\left(\mathrm{R}=4-\mathrm{CF}_{3}\right.$, 4-OMe) did not strongly influence the enantioselectivity of 37b, c. As shown in $\mathbf{3 7} \mathbf{d}-\mathbf{j}$, a c-Hex group decreased the ee of the HCN adducts, which suggests that the steric bulk of $\mathrm{R}$ plays an important role in face selectivity. In the case of a primary alkyl group, the reaction was completed within $15 \mathrm{~min}$, although much lower ee was observed $(\mathbf{3 7 k}, \mathbf{l})$. This suggests that modes B-D are possible because of less-bulky substituents to decrease the face and/or regioselectivity.

One of the synthetic applications for this chirality transfer is enantioselective hydrocyanative 5-exo cyclization (Chart 17). The chiral allene-yne is a precursor of the optically active 
heterocycle (10n) via an optically active Ni(II) intermediate. The reaction using $(R)-9 n(92 \%$ ee) proceeded smoothly to give $(S)-10 \mathbf{n}^{54)}$ with $64 \%$ ee, which suggests that optically active allyl $\mathrm{Ni}(\mathrm{II})$ intermediates $(\mathbf{1 1 n})$ could be generated from the axial chirality of $(R)-\mathbf{9 n}$.

\section{Conclusion}

The new reactions described here all originate from the unique reactivity of allene, and these transformations should be useful for the synthesis of various cyclic and acyclic molecules. This review shows that a simple $\mathrm{C}=\mathrm{C}=\mathrm{C}$ functionality is a key structure in nickel catalysis and natural product synthesis. Studies with D-labeling and chirality transfer were important for revealing the reaction mechanism and regioselectivity. These results demonstrate the utility of both $\mathrm{Ni}$ catalysis and allenyl functionalities in chemical transformations.

Acknowledgments The author thanks Prof. Atsushi Nishida and Prof. Shinji Harada (Chiba University) for their helpful support and fruitful discussions. He also appreciates the following collaborators for their efforts: Dr. Yuka Amako; Dr. Hiroto Hori; Mr. Tomohiro Igarashi; Dr. Xiaofei Yang; and Mr. Koki Matsumoto. This project was financially supported by the Japan Society for the Promotion of Science (JSPS), Uehara Memorial Foundation, and Naito Foundation.

Conflict of Interest The author declares no conflict of interest.

\section{References and Notes}

1) Fleming F. F., Yao L., Ravikumar P. C., Funk L., Shook B. C., J. Med. Chem., 53, 7902-7917 (2010).

2) Bini L., Müller C., Vogt D., ChemCatChem, 2, 590-608 (2010). 3) Bini L., Müller C., Vogt D., Chem. Commun., 46, 8325-8334 (2010). 4) Ye F., Chen J., Ritter T., J. Am. Chem. Soc., 139, 7184-7187 (2017). 5) Gaspar B., Carreira E. M., Angew. Chem. Int. Ed., 46, 4519-4522 (2007).

6) Nakao Y., Oda S., Hiyama T., J. Am. Chem. Soc., 126, 13904-13905 (2004).

7) Minami Y., Yoshiyasu H., Nakao Y., Hiyama T., Angew. Chem. Int. Ed., 52, 883-887 (2013).

8) Hirata Y., Yada A., Morita E., Nakao Y., Hiyama T., Ohashi M., Ogoshi S., J. Am. Chem. Soc., 132, 10070-10077 (2010).

9) Nishihara Y., Inoue Y., Itazaki M., Takagi K., Org. Lett., 7, 2639 2641 (2005).

10) Nakao Y., Yada A., Ebata S., Hiyama T., J. Am. Chem. Soc., 129, 2428-2429 (2007).

11) Nakao Y., Yukawa T., Hirata Y., Oda S., Satoh J., Hiyama T., J. Am. Chem. Soc., 128, 7116-7117 (2006).

12) Nakao Y., Hirata Y., Tanaka M., Hiyama T., Angew. Chem. Int. Ed., 47, 385-387 (2008)

13) Miyazaki Y., Ohta N., Semba K., Nakao Y., J. Am. Chem. Soc., 136, 3732-3735 (2014)

14) Koester D. C., Kobayashi M., Werz D. B., Nakao Y., J. Am. Chem. Soc., 134, 6544-6547 (2012).

15) Wang X., Studer A., J. Am. Chem. Soc., 138, 2977-2980 (2016).

16) Chatani N., Hanafusa T., J. Chem. Soc., Chem. Commun., 838-839 (1985).

17) Chatani N., Horiuchi N., Hanafusa T., J. Org. Chem., 55, 3393-3395 (1990).

18) Suginome M., Yamamoto A., Murakami M., J. Am. Chem. Soc., 125, 6358-6359 (2003)

19) Kamiya I., Kawakami J., Yano S., Nomoto A., Ogawa A., Organo- metallics, 25, 3562-3564 (2006).

20) Murai M., Hatano R., Kitabata S., Ohe K., Chem. Commun., 47, 2375-2377 (2011)

21) Sakata N., Sasakura K., Matsushita G., Okamoto K., Ohe K., Org. Lett., 19, 3422-3425 (2017).

22) Obora Y., Baleta A. S., Tokunaga M., Tsuji Y., J. Organomet. Chem., 660, 173-177 (2002).

23) Arai S., Sato T., Koike Y., Hayashi M., Nishida A., Angew. Chem. Int. Ed., 48, 4528-4531 (2009).

24) Arai S., Koike Y., Hada H., Nishida A., J. Am. Chem. Soc., 132, 4522-4523 (2010).

25) Arai S., Nishida A., Synlett, 23, 2880-2893 (2012).

26) Ilchenko N. O., Janson P. G., Szabó K. J., J. Org. Chem., 78, $11087-$ 11091 (2013).

27) Barrado A. G., Zielinski A., Goddard R., Alcarazo M., Angew. Chem. Int. Ed., 56, 13401-13405 (2017).

28) Higashimae S., Kurata D., Kawaguchi S. I., Kodama S., Sonoda M., Nomoto A., Ogawa A., J. Org. Chem., 83, 5267-5273 (2018).

29) Nemoto K., Nagafuchi T., Tominaga K., Sato K., Tetrahedron Lett., 57, 3199-3203 (2016)

30) Fang X., Yu P., Morandi P., Science, 351, 832-836 (2016).

31) Jackson W. R., Lovel C. G., J. Chem. Soc., Chem. Commun., 12311232 (1982).

32) Saha B., RajanBabu T. V., Org. Lett., 8, 4657-4659 (2006).

33) Falk A., Göderz A.-L., Schmalz H.-G., Angew. Chem. Int. Ed., 52, 1576-1580 (2013)

34) Igarashi T., Arai S., Nishida A., J. Org. Chem., 78, 4366-4372 (2013).

35) Yamamoto A., Suginome M., J. Am. Chem. Soc., 127, 15706-15707 (2005).

36) Arai S., Amako Y., Yang X., Nishida A., Angew. Chem. Int. Ed., 52, 8147-8150 (2013)

37) Amako Y., Hori H., Arai S., Nishida A., J. Org. Chem., 78, $10763-$ 10775 (2013).

38) Zhang M., Watanabe K., Tsukamoto M., Shibuya R., Morimoto H., Ohshima T., Chemistry, 21, 3937-3941 (2015).

39) Takita S., Yokoshima S., Fukuyama T., Org. Lett., 13, 2068-2070 (2011).

40) Inoki S., Kato K., Isayama S., Mukaiyama T., Chem. Lett., 19 1869-1872 (1990).

41) Trost B. M., Rudd M. T., J. Am. Chem. Soc., 127, 4763-4776 (2005).

42) Yang X., Arai S., Nishida A., Adv. Synth. Catal., 355, 2974-2981 (2013).

43) Kang S.-K., Baik T.-G., Kulak A. N., Ha Y.-H., Lim Y., Park J., J. Am. Chem. Soc., 122, 1529-1530 (2000).

44) Sakakibara Y., Matsuzaka S., Nagamine S., Sakai S., Uchino N., Nippon Kagaku Kaishi, 1985, 409-415 (1985).

45) Arai S., Hori H., Amako Y., Nishida A., Chem. Commun., 51, 7493-7496 (2015).

46) Hori H., Arai S., Nishida A., Adv. Synth. Catal., 359, 1170-1176 (2017).

47) Solé D., Bennasar M. L., Roca T., Valldosera M., Eur. J. Org. Chem., 2016, 1355-1366 (2016).

48) Hsu S. W., Cheng H. Y., Huang A. C., Ho T. L., Hou D. R., Eur. J. Org. Chem., 2014, 3109-3115 (2014).

49) Grover H. K., Kerr M. A., Synlett, 26, 815-819 (2015).

50) Bajtos B., Pagenkopf B. L., Eur. J. Org. Chem., 2009, 1072-1077 (2009).

51) Matsumoto K., Arai S., Nishida A., Tetrahedron, 74, 2865-2870 (2018).

52) Neff R. K., Frantz D. E., Tetrahedron, 71, 7-18 (2015).

53) Amako Y., Arai S., Nishida A., Org. Biomol. Chem., 15, 1612-1617 (2017).

54) $\overline{\mathrm{CCDC}} 1521006$ contains the supplementary crystallographic data. These data can be obtained free of charge from the Cambridge Crystallographic Data Centre via www.ccdc.cam.ac.uk/data_request/cif. 